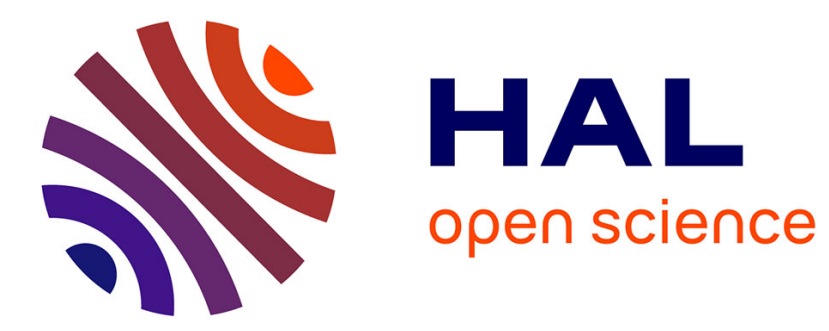

\title{
Rotation, narrowing, and preferential reactivation of brittle structures during oblique rifting
}

\author{
Guillaume Duclaux, Ritske Huismans, Dave May
}

\section{To cite this version:}

Guillaume Duclaux, Ritske Huismans, Dave May. Rotation, narrowing, and preferential reactivation of brittle structures during oblique rifting. Earth and Planetary Science Letters, 2020, 531, pp.115952. 10.1016/j.epsl.2019.115952 . hal-02382993

\section{HAL Id: hal-02382993 \\ https://hal.science/hal-02382993}

Submitted on 27 Nov 2019

HAL is a multi-disciplinary open access archive for the deposit and dissemination of scientific research documents, whether they are published or not. The documents may come from teaching and research institutions in France or abroad, or from public or private research centers.
L'archive ouverte pluridisciplinaire $\mathbf{H A L}$, est destinée au dépôt et à la diffusion de documents scientifiques de niveau recherche, publiés ou non, émanant des établissements d'enseignement et de recherche français ou étrangers, des laboratoires publics ou privés.

\section{(1) (1) $\$$}

Distributed under a Creative Commons Attribution - NonCommercial - NoDerivatives $\mid 4.0$ 


\title{
Rotation, narrowing, and preferential reactivation of brittle structures during oblique rifting
}

\author{
Guillaume Duclaux $^{\mathrm{a}, \mathrm{b}, *}$, Ritske S. Huismans ${ }^{\mathrm{a}}$, Dave A. May ${ }^{\mathrm{c}}$ \\ a Department of Earth Science, University of Bergen, Allégaten 41, 5007 Bergen, Norway \\ b Université Côte d'Azur, OCA, CNRS, IRD, Géoazur, 250 rue Albert Einstein, 06560 Valbonne, France \\ c Department of Earth Sciences, University of Oxford, South Parks Road, Oxford OX1 3AN, United Kingdom
}

\section{A R T I C L E I N F O}

\section{Article history:}

Received 8 October 2019

Accepted 5 November 2019

Available online $\mathrm{xxxx}$

Editor: A. Yin

\section{Keywords:}

rift systems

numerical modeling

tectonics

normal faults

transtension

\begin{abstract}
A B S T R A C T
Occurrence of multiple faults populations with contrasting orientations in oblique continental rifts and passive margins has long sparked debate about relative timing of deformation events and tectonic interpretations. Here, we use high-resolution three-dimensional thermo-mechanical numerical modeling to characterize the evolution of the structural style associated with varying geometries of oblique rifting in a layered continental lithosphere. Automatic analysis of the distribution of active extensional shear zones at the surface of the model demonstrates a characteristic sequence of deformation. Phase 1 with initial localization of deformation and development of wide moderately oblique en-échelon grabens limited by extensional shear zones oriented close to orthogonal to $\sigma_{3}$ trend. Subsequent widening of the grabens is accompanied by progressive rotation of the phase 1 extensional shear zones to an orientation sub-orthogonal to the plate motion direction. Phase 2 is characterized by narrowing of active deformation resulting from thinning of the continental mantle lithosphere and development of a second-generation of extensional shear zones. During phase 2 deformation localizes both on plate motion direction-orthogonal structures that reactivate rotated phase 1 shear zones, and on new moderately oblique structures parallel to $\sigma_{2}$. Finally, phase 3 consists in the oblique rupture of the continental lithosphere and produces an oceanic domain where oblique ridge segments are linked with highly oblique accommodation zones. We conclude that while new structures form and trend parallel to $\sigma_{2}$ in an oblique rift, progressive rotation and long-term slip along phase 1 structures promotes orthorhombic fault systems, which accommodate upper crustal extension and control oblique passive margin architecture. The distribution, orientation, and evolution of frictional-plastic structures observed in our models consistent with documented fault populations in the Main Ethiopian Rift and the Gulf of Aden conjugate passive margins, both of which developed in moderately oblique extensional settings.
\end{abstract}

(c) 2019 The Author(s). Published by Elsevier B.V. This is an open access article under the CC BY-NC-ND license (http://creativecommons.org/licenses/by-nc-nd/4.0/).

\section{Introduction}

The obliquity between horizontal plate motion direction and nascent or existing divergent plate boundaries prompts the development of oblique continental rift and oceanic domains in which deformation is typically transtensional (Dewey et al., 1998; Philippon and Corti, 2016; Brune et al., 2018). Large stretching in the obliquely extending brittle crust is primarily achieved by the accumulation of displacement on fault networks with fault populations of varying orientations and lifespan, distributed over tens to hundreds of kilometer-wide regions (e.g., Agostini et al., 2009). Unraveling the relative timing and tectonic interpretations of juxtaposed fault populations in oblique rift systems is critical to better

\footnotetext{
* Corresponding author.

E-mail address: duclaux@unice.fr (G. Duclaux).
}

understand the architecture of passive margins, and has been the topic of numerous studies in the Gulf of California (Withjack and Jamison, 1986; Umhoefer and Stone, 1996; Lizarralde et al., 2007), the Gulf of Aden (Withjack and Jamison, 1986; Leroy et al., 2013; Brune and Autin, 2013; Autin et al., 2013), the Malawi and Main Ethiopian rifts in East Africa (Chorowicz and Sorlien, 1992; Corti et al., 2013), and several grabens in the northern North Sea (Knudsen et al., 1997; Fossen et al., 2016). In active oblique rift systems, fault-slip statistical analyses, combined with geochronology have helped deciphering fault population records (e.g., Bergerat et al., 1990; Bellahsen et al., 2013). However, these methods are not directly applicable to passive margins studies where structures are generally buried under thick post-rift sediments and interpreted from geophysical data. Moreover, statistical analyses of fault-slip data have to be applied with caution in mature tectonic systems. Accumulated deformation between faults, and at depth, introduce additional displacements, rigid rotations and internal strains, mak- 


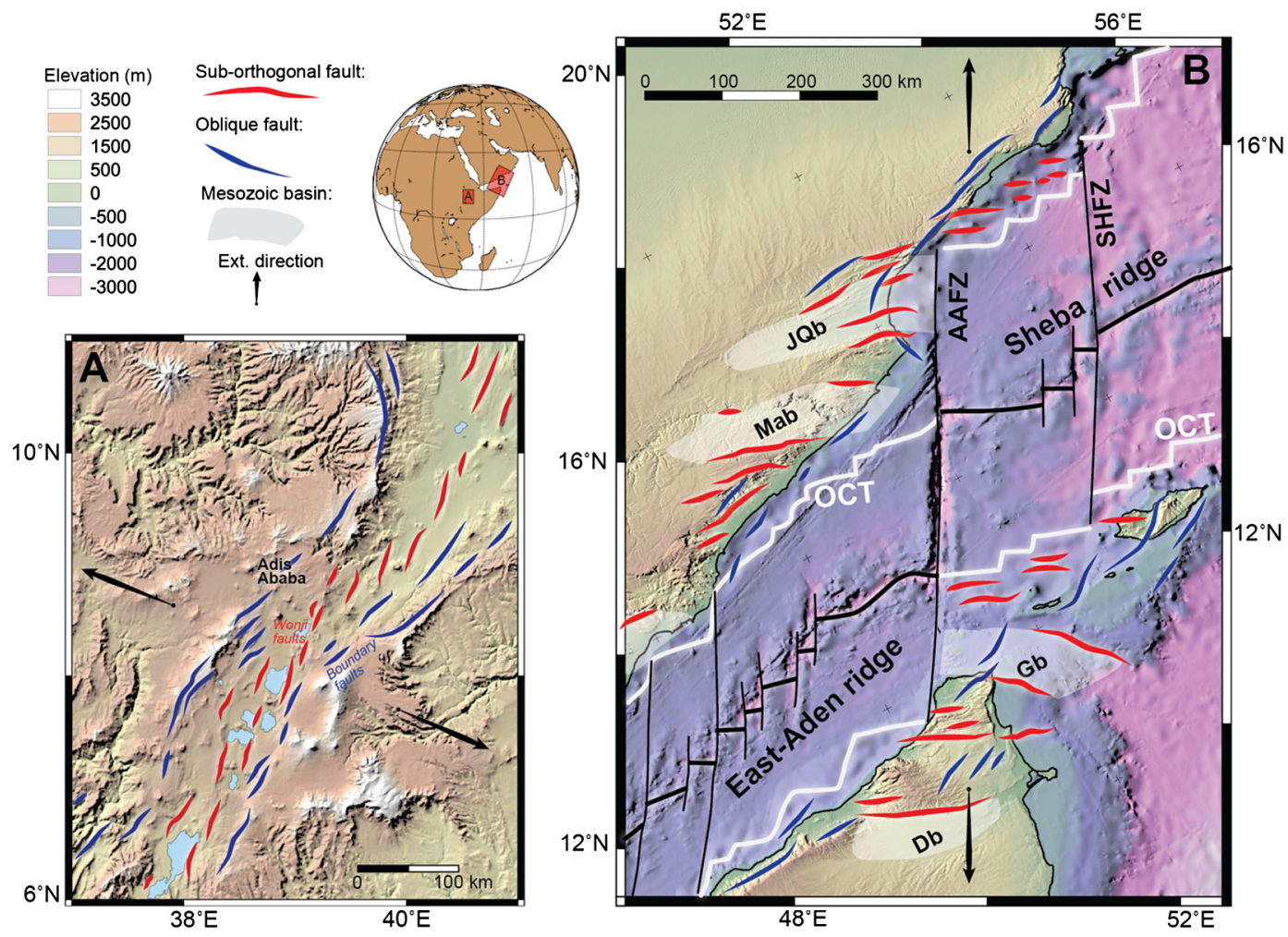

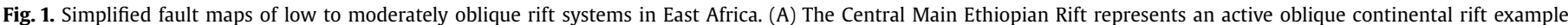

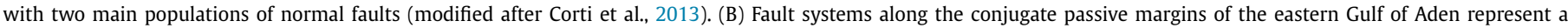

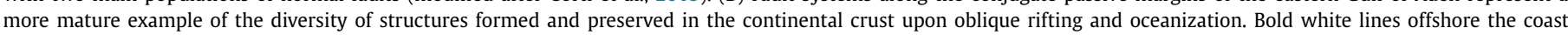
represent the Ocean-Continent Transition (OCT) recognized in the region (modified after Bellahsen et al., 2013).

ing interpretation of the regional stress pattern related to fault development debatable (Gapais et al., 2000).

Two examples of oblique extension in continental rifts and passive margin systems illustrate the range of surface structures' trends, varying from moderately oblique to orthogonal to the extension direction. The East African Cenozoic rifts have developed mainly within wide Proterozoic belts. Among these segments, the Main Ethiopian Rift (MER) deformation is partitioned between two sets of normal faults (Fig. 1A). The early Boundary faults trending obliquely to sub-orthogonal to the plate motion direction, that formed during the Mio-Pliocene marking the limit of the wide curved rift depression, are most likely related to inherited crustal architecture. The late Quaternary extension-orthogonal Wonji faults correspond to the active structures distributed enéchelon within the rift depression (e.g., Agostini et al., 2011; Corti et al., 2013; Philippon et al., 2015). The Gulf of Aden conjugate rifted margin system (Fig. 1B) represents a more evolved example of oblique extension with the main passive margin extensional structures and ocean spreading at about $55^{\circ}$ obliquity with respect to the trend of the Gulf (Leroy et al., 2013). En-échelon extensional basins developed during a Mesozoic rifting phase provide structural control on the subsequent oblique rifting that resulted in the formation of the Gulf of Aden during the Oligo-Miocene (Autin et al., 2013; Bellahsen et al., 2013). To the East of the Gulf, fault populations of varying orientations have been identified on the conjugate passive margins (Autin et al., 2010) and relate to the progressive opening of the Aden rift system.

Fortunately, over the past decades, modeling approaches have successfully been used to investigate continental rifting and to constrain the underlying mechanisms that control the structural style of deformation at divergent plate boundaries. Analog experiments have offered high-resolution understanding of three-dimensional (3D) fault development in a wide range of extensional settings, including oblique rifting (Withjack and Jamison, 1986; Tron and Brun, 1991; Clifton et al., 2000; McClay et al., 2002; Agostini et al., 2009; Autin et al., 2010; Zwaan et al., 2016). Only recently, owing to the progress of computational methods and increased high performance computing capacity, thermo-mechanical numerical models have been used to explore rifting in 3D, allowing comparisons with analog experiments and natural rift systems (van Wijk, 2005; Allken et al., 2012; Brune et al., 2012; Brune and Autin, 2013; Brune, 2014; Liao and Gerya, 2015; Mondy et al., 2017; Le Pourhiet et al., 2017). However, the relatively coarse resolution of the numerical models used to date has constituted an important limitation for understanding the structural style and 3D aspects of rift and passive margin formation.

Here, we use high-resolution 3D thermo-mechanical modeling to investigate the structural style of deformation during oblique rift and passive margin formation. We focus on relative timing and distribution of localized surface deformation during oblique rift development in a simplified layered lithosphere. An initial lithospheric weakness striking at varying obliquity from the horizontal plate motion direction is prescribed in the models using a large weak zone that allows intra-rift shear zones (i.e. regions of localized deformation, similar to surface faults, with a strain rate second invariant above $5 \times 10^{-15} \mathrm{~s}^{-1}$ ) to form and evolve freely. Quantitative analysis of the active surface deformation allows us to conclude that while shear zones trend parallel to $\sigma_{2}$ as predicted by Andersonian theory of faulting, progressive rotation and reactivation of early extensional structures with different orientations are critical to accommodate upper crustal extension and control oblique rift and passive margin architecture. We infer three characteristic phases of deformation from the model results, discuss each phase in terms of their underlying controls, and compare those with observations from natural oblique divergent systems along the active MER, and the Gulf of Aden passive margins. 

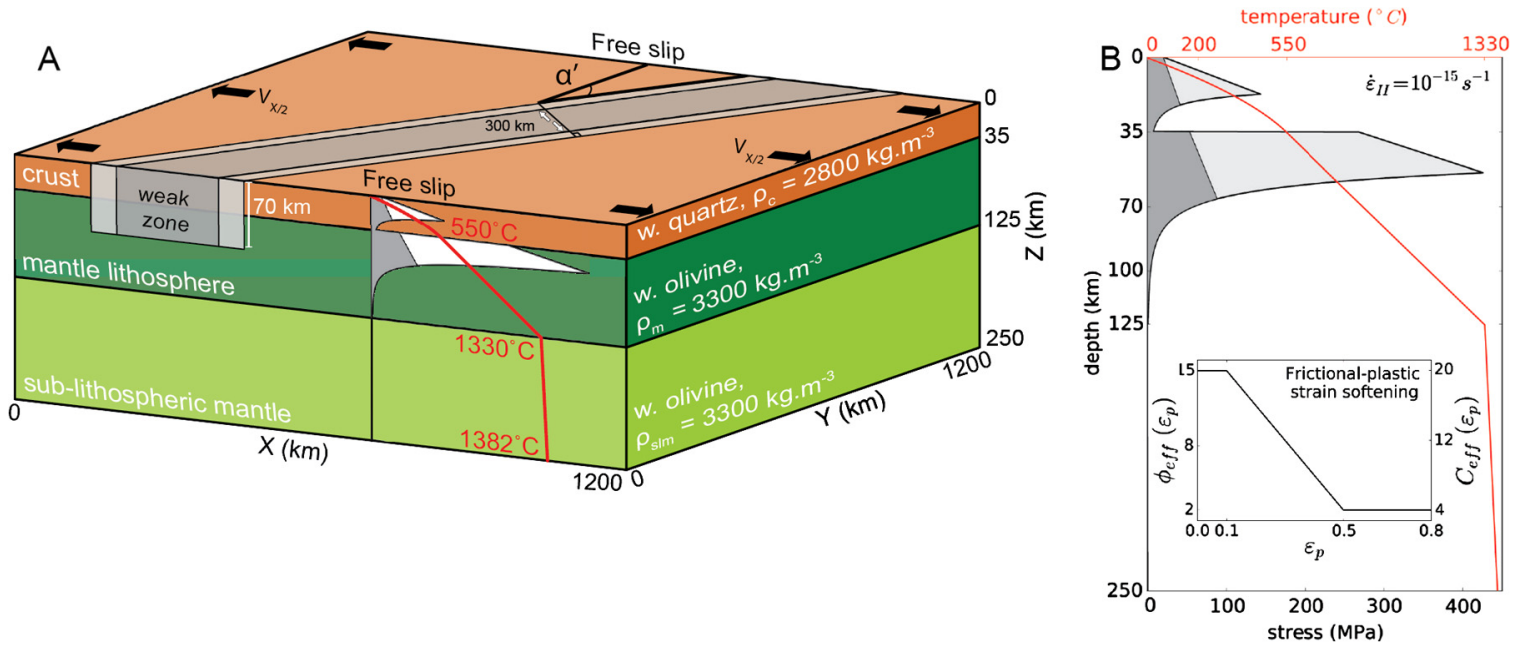

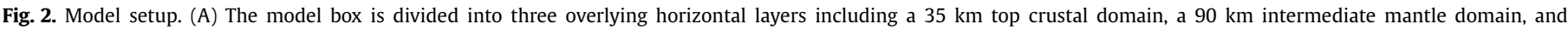

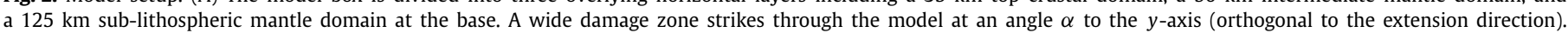

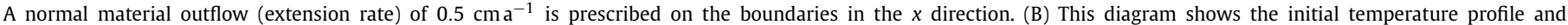

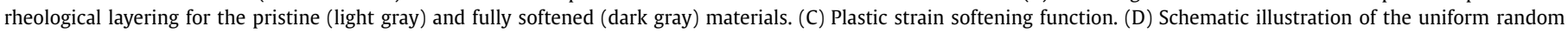
distribution of plastic strain imposed in the weak zone.

\section{Methodology}

We solve the governing equations for a highly viscous incompressible fluid with a visco-plastic flow law to investigate the extension of a layered lithosphere in 3D using the massively-parallel arbitrary Lagrangian-Eulerian (ALE) open-source finite element code, pTatin3D (May et al., 2014, 2015) (see supplement for details on numerical method). The model domain spans $1200 \times 1200 \mathrm{~km}$ horizontally, and $250 \mathrm{~km}$ vertically, with a two-layer $125 \mathrm{~km}$ thick lithosphere consisting of $35 \mathrm{~km}$ thick crust and $90 \mathrm{~km}$ thick mantle lithosphere, with $125 \mathrm{~km}$ thick sub-lithospheric mantle below (Fig. 2). Each layer is defined by a unique set of material parameters, combining temperature dependent non-linear viscous and strain-weakening frictional-plastic rheologies that allow for localization of deformation (e.g. Huismans and Beaumont, 2003, 2007). The conservation of mass and momentum is:

$\operatorname{div}\left(2 \eta_{e f f} \dot{\boldsymbol{\varepsilon}}\right)-\operatorname{grad}(p)=\boldsymbol{F}$

$\operatorname{div}(\boldsymbol{u})=0$

where $\dot{\boldsymbol{\varepsilon}}$ is the strain-rate tensor, $p$ is the pressure, $\boldsymbol{u}$ the velocity, $\eta_{\text {eff }}$ the effective viscosity, and $\boldsymbol{F}$ the body force, with $\boldsymbol{F}=-\rho \mathbf{g}$, with $\mathbf{g}$ the standard acceleration due to gravity. Densities of crust and mantle depend on temperature with $\rho=\rho_{0}\left(1-\alpha_{T}\left(T-T_{0}\right)\right)$, where $\alpha_{T}$ represents the volumetric thermal expansion coefficient, $T_{0}$ is the surface temperature $\left(0^{\circ} \mathrm{C}\right)$ and $T$ is the temperature at depth.

When the state of stress is below the frictional-plastic yield the flow is viscous and is specified by temperature-dependent nonlinear power law rheologies based on laboratory measurements on 'wet' quartz (Gleason and Tullis, 1995) and 'wet' olivine (Karato and $\mathrm{Wu}, 1993)$. The effective viscosity, $\eta_{\text {eff }}$, in the power-law rheology is of the general form:

$\eta_{\text {eff }}=f A^{-1 / n}\left(\dot{\varepsilon}_{I I}\right)^{(1-n) / 2 n} e^{((Q+p V) / n R T)}$

where $\dot{\varepsilon}_{I I}$ is the second invariant of the strain rate tensor $\left(\dot{\varepsilon}_{i j} \dot{\varepsilon}_{i j}\right) / 2, n$ is the power law exponent, $A$ is the pre-exponential scaling factor, $f$ is a scaling factor that is used to produce strong and weak versions of the nominal olivine and wet quartz rheologies, $Q$ is the activation energy, $V$ is the activation volume, which makes the viscosity dependent on pressure, $p, T$ is the temperature, $R$ is the universal gas constant. $A, n, Q$ and $V$ are derived from the laboratory experiments and the parameter values are listed in Table 1.

Frictional-plastic yielding is modeled with a pressure-dependent Drucker-Prager yield criterion. Yielding occurs when:

$\sigma_{Y}=\left(J_{2}^{\prime}\right)^{1 / 2}=C \cos \phi_{e f f}+p \sin \phi_{e f f}$

where $J_{2}^{\prime}=\left(\sigma_{i j}^{\prime} \sigma_{i j}^{\prime}\right) / 2$ is the second invariant of the deviatoric stress tensor $\sigma^{\prime}, \phi_{e f f}$ is the effective internal angle of friction, and $C$ is the cohesion. With appropriate choices of $C$ and $\phi_{e f f}$ this yield criterion can approximate frictional sliding in rocks. Plastic flow is incompressible. Strain softening (Huismans and Beaumont, $2003,2007)$ is introduced by a linear decrease of $\phi_{e f f}\left(\varepsilon_{p}\right)$ from $15^{\circ}$ to $2^{\circ}$ and $C_{e f f}\left(\varepsilon_{p}\right)$ from $20 \mathrm{MPa}$ to $4 \mathrm{MPa}$ (Fig. 2B, C, Table 1 ), where $\varepsilon_{p}$ is the accumulated plastic strain. This linear strain softening is applied for values of accumulated plastic strain between 10 and 50\%. Plastic strain represents an integrated, tensorial invariant measure of the deformation, which has occurred due to plastic yielding. Thus, the quantity $\varepsilon_{p}$ can be regarded as a simplified measure of material damage. The evolution of plastic strain is given by:

$\frac{D \varepsilon_{p}}{D t}= \begin{cases}\sqrt{\dot{\varepsilon}_{I I}}, & \text { if } \eta_{e f f}>\sigma_{Y} / 2 \dot{\varepsilon}_{I I}^{1 / 2} \\ 0, & \text { otherwise }\end{cases}$

Both non-linear viscous and frictional-plastic rheologies have been extensively tested in numerical experiments (e.g. Huismans and Beaumont, 2002, 2003, 2011). The effective viscosity $\eta_{\text {eff }}$ is limited to a range of $10^{18}$ to $10^{27}$ Pas.

We impose a $300 \mathrm{~km}$ wide weak zone, where the width is measured perpendicular to the weak zone strike, extending through the model at either $30^{\circ}$ (low obliquity model M1), $45^{\circ}$ (moderate obliquity model M2) or $60^{\circ}$ (high obliquity model M3) with respect to the Y-axis. Here we define the obliquity for each model $\left(\alpha^{\prime}\right)$ as the angle between the orthogonal to the weak zone trend and the direction of extension, similarly to Brune et al. (2012) or Agostini et al. (2009). Within this zone we introduce a random value of initial plastic strain $\left(\varepsilon_{p}\right)$ ranging between 0 and 0.50 to the material particles present in the model (initial plastic distribution is illustrated in Fig. S10). The central zone is bounded on 
Table 1

Model parameters values.

\begin{tabular}{|c|c|c|}
\hline Parameter & Symbol & Value \\
\hline \multicolumn{3}{|l|}{ Rheological Parameters } \\
\hline Angle of internal friction & $\phi\left(\varepsilon_{p}\right)$, and strain range of softening & $15^{\circ}-2^{\circ}, 0.1-0.5$ \\
\hline Cohesion & $C\left(\varepsilon_{p}\right)$ & $20 \mathrm{MPa}-4 \mathrm{MPa}$ \\
\hline \multicolumn{3}{|l|}{ Wet Quartz ${ }^{\text {[GET, 1995] }}$} \\
\hline Power law exponent & $n$ & 4.0 \\
\hline Activation energy & $Q$ & $223 \times 10^{3} \mathrm{~J} \mathrm{~mol}^{-1}$ \\
\hline Initial constant & $A$ & $8.5737 \times 10^{-28} \mathrm{~Pa}^{-n} \mathrm{~s}^{-1}$ \\
\hline Activation volume & $V$ & $0 \mathrm{~m}^{3} \mathrm{~mol}^{-1}$ \\
\hline \multirow{2}{*}{\multicolumn{3}{|c|}{ Wet Olivine [KEW, 1993] $^{\left[K{ }^{2}\right.}$}} \\
\hline & & \\
\hline Power law exponent & $n$ & 3.0 \\
\hline Activation energy & $Q$ & $430 \times 10^{3} \mathrm{~J} \mathrm{~mol}^{-1}$ \\
\hline Initial constant & $A$ & $1.393 \times 10^{-14} \mathrm{~Pa}^{-n} \mathrm{~s}^{-1}$ \\
\hline Activation volume & $V$ & $15 \times 10^{-6} \mathrm{~m}^{3} \mathrm{~mol}^{-1}$ \\
\hline Mantle lithosphere scaling factor & $f_{m l}$ & 5 \\
\hline Sub-lithospheric mantle scaling factor & $f_{\text {slm }}$ & 1 \\
\hline Universal gas constant & $R$ & $8.3144 \mathrm{~J} \mathrm{~mol}^{-1} \mathrm{~K}^{-1}$ \\
\hline \multicolumn{3}{|l|}{ Thermal Parameters } \\
\hline Conductivity & $k$ & $2.25 \mathrm{~W} \mathrm{~m}^{-1} \mathrm{~K}^{-1}$ \\
\hline Specific heat capacity & $C_{p}$ & $1000 \mathrm{~J} \mathrm{~kg}^{-1} \mathrm{~K}^{-1}$ \\
\hline Crustal radioactive heat production & $A_{R}$ & $0.9 \times 10^{-6} \mathrm{Wm}^{-3}$ \\
\hline Volume coefficient of thermal expansion & $\alpha_{T}$ & $2 \times 10^{-5} \mathrm{~K}^{-1}$ \\
\hline Surface temperature & $T_{0}$ & $0^{\circ} \mathrm{C}$ \\
\hline Initial Moho temperature & $T_{m}$ & $550^{\circ} \mathrm{C}$ \\
\hline Base Lithosphere temperature & $T_{l}$ & $1330^{\circ} \mathrm{C}$ \\
\hline Basal temperature & $T_{a}$ & $1382^{\circ} \mathrm{C}$ \\
\hline \multicolumn{3}{|l|}{ Densities $\left(T_{0}=0^{\circ} \mathbf{C}\right)$} \\
\hline Crustal density & $\rho_{c}$ & $2800 \mathrm{~kg} \mathrm{~m}^{-3}$ \\
\hline Mantle density & $\rho_{m}$ & $3300 \mathrm{~kg} \mathrm{~m}^{-3}$ \\
\hline Sub lithosphere mantle density & $\rho_{\text {slm }}$ & $3300 \mathrm{~kg} \mathrm{~m}^{-3}$ \\
\hline \multicolumn{3}{|l|}{ Dimensions and Boundary Condition } \\
\hline Base of crust & & $35 \mathrm{~km}$ \\
\hline Base of mantle lithosphere & & $120 \mathrm{~km}$ \\
\hline Base of the model & $z_{d}$ & $250 \mathrm{~km}$ \\
\hline Horizontal dimensions of the model & $x_{d}, y_{d}$ & $1200 \mathrm{~km}$ \\
\hline Extension velocity & $V_{x} / 2$ & $0.5 \mathrm{~cm} \mathrm{a}^{-1}$ (half rate) \\
\hline Top boundary condition & & Stress free surface \\
\hline$x$-normal side boundary conditions & & Free slip, normal velocity $V_{x}$ \\
\hline$y$-normal side boundary conditions & & Free slip, zero normal velocity \\
\hline Basal boundary conditions & $V_{z}$ & $\begin{array}{l}\text { Free slip, normal velocity balancing } x \text {-normal sides outflow } \\
{\left[V_{z}=\left(V_{x} * z_{d}\right) / x_{d}\right]}\end{array}$ \\
\hline Model 1 obliquity (angle between weak zone trend and $y$-axis) & $\alpha_{1}^{\prime}$ & $30^{\circ}$ \\
\hline Model 2 obliquity & $\alpha_{2}^{\prime}$ & $45^{\circ}$ \\
\hline Model 3 obliquity & $\alpha_{3}^{\prime}$ & $60^{\circ}$ \\
\hline
\end{tabular}

each side by a $50 \mathrm{~km}$ wide buffer zone where the maximum random value of $\varepsilon_{p}$ gradually decreases from 0.50 to 0 following an arctangent function of the distance to the central zone. This weak zone introduces a discontinuity in the model and promotes strain localization and the development of the prospective rift.

In our models the model domain evolves through time. Using our ALE formulation, we allow the free surface to be advected with the fluid velocity, and prescribe all other boundaries to remain stationary. In practice we: extract a surface mesh; advect its coordinates with $u$; and project the updated $z$-coordinate of the surface mesh onto the vertices within the original mesh defined on the upper surface. Lastly, we apply a column wise remeshing in the vertical direction $(z)$, from the base to the free surface. A normal material outflow of $0.5 \mathrm{cma}^{-1}$ is prescribed on the boundaries in the $x$-direction, representing a full rate of extension $V_{x}$ of $1 \mathrm{cma}^{-1}$. Free slip with zero normal velocity is imposed on the front and rear side boundaries of the model normal to the $y$-direction. At the base of the model, we apply a constant and spatially uniform inflow velocity that balances lateral outflow such that the volume of the model domain remains constant.

In addition to solving the equilibrium equations for viscousplastic flows in three dimensions, we also solve for the ther- mal evolution of the model. The model initial temperature field is laterally uniform (Fig. 2), and increases with depth from the surface, $T_{0}=0{ }^{\circ} \mathrm{C}$, to the base of the crust, $T_{m}=550^{\circ} \mathrm{C}$, following a stable geotherm for uniform crustal heat production, $A_{R}=$ $0.9 \mu \mathrm{W} \mathrm{m}^{-3}$ and a basal heat flux, $q_{m}=19.5 \mathrm{~mW} \mathrm{~m}^{-2}$. The mantle lithosphere has a uniform geothermal gradient of $8.6^{\circ} \mathrm{C} \mathrm{km}^{-1}$, while a temperature-dependent conductivity is imposed in the sub-lithospheric mantle where the temperature gradient is adiabatic at $0.4^{\circ} \mathrm{C} \mathrm{km}^{-1}$. All materials have a thermal conductivity of $2.25 \mathrm{~W} \mathrm{~m}^{-1} \mathrm{~K}^{-1}$ at temperatures below $1330^{\circ} \mathrm{C}$ (i.e. the base of the continental lithosphere at model initiation). Thermal conductivity linearly increases to $48.75 \mathrm{~W} \mathrm{~m}^{-1} \mathrm{~K}^{-1}$ at $1350{ }^{\circ} \mathrm{C}$, corresponding to scaling the thermal conductivity by the Nusselt number of upper mantle convection (Pysklywec and Beaumont, 2004). Thanks to this method, the enhanced conductivity maintains a nearly constant heat flux at the lithosphere base and an adiabatic temperature gradient in the sub-lithospheric mantle. Thermal boundary conditions are specified basal temperature of $1382^{\circ} \mathrm{C}$ at $z=250 \mathrm{~km}$, insulated lateral boundaries, and prescribed as a Dirichlet condition to be $0^{\circ} \mathrm{C}$ on the upper boundary. The evolu- 
tion of temperature $T$ is given by the energy conservation equation:

$\rho_{0} C_{p}\left(\frac{\partial T}{\partial t}+\boldsymbol{u} \cdot \nabla T\right)=\nabla \cdot(k \nabla T)+A_{R}+V_{Z} \alpha_{T} \rho_{0} \mathbf{g} T$

where $\boldsymbol{u}$ is the velocity of the flow, $A_{R}$ the radiogenic heat production, and $k$ the thermal conductivity. The last term in the heat balance equation is the temperature correction for adiabatic heating and cooling when material moves vertically at velocity $V_{z}$ (Warren et al., 2008). The mechanical and thermal systems are coupled through the temperature dependence of viscosity and density and are solved sequentially at each model time step.

\section{Results}

We first present three rift models M1, M2 and M3 with varying obliquity focusing on the style of deformation and rift structure at the surface and at depth. Although we impose the obliquity of the weak zone for each model $\left(\alpha^{\prime}\right.$, the angle between the orthogonal to the weak zone trend and the direction of extension), the obliquity of the rift trend ( $\alpha$, the angle between the orthogonal to the rift structures trend and the direction of extension) is measured based on the model results. This is followed by analysis of the evolving trend of the frictional-plastic shear zones at the surface, rift width, and crust and mantle thinning patterns. Orientations and lengths of individual surface frictional-plastic shear zones is measured every $250 \mathrm{ka}$ from the three models through an automated sequential mapping method based on $\dot{\varepsilon}_{I I}$, using a suite of python functions designed for shape recognition and image processing. The orientation and length of individual shear zone are extracted. The distribution of shear zones orientations, weighted by the length of individual shear zone is then used to study faulting pattern evolution of each model (see supplementary material for details).

\section{Model 1 (M1): Low obliquity (weak zone obliquity $=30^{\circ}$ )}

At $4 \mathrm{Ma}$ extension results in a wide oblique depression limiting a zone of distributed deformation that forms at the surface (Fig. 3A). The strike and width of the depression are consistent with the imposed oblique weak zone geometry. Conjugate normal shear zones, initiated at the internal corner of the weak zone and the model edges, have propagated and linked forming a set of two elongated en-échelon $110 \mathrm{~km}$-wide grabens. In the central region of the model the active strike of the shear zones varies between $0^{\circ}$ and $12^{\circ}$, with a peak around $9^{\circ}$, consistent with the minimum instantaneous horizontal strain direction, which is a proxy for the intermediate principal stress $\sigma_{2}$ (e.g., inset rose diagram Fig. 3A). At 7.5 Ma (Fig. 3B) extension has widened the first generation grabens in the central region of the model up to about $140 \mathrm{~km}$. The strike of the active shear zones remains moderately oblique at about $10^{\circ}$, whereas the minimum instantaneous horizontal strain direction rotates counterclockwise to $6^{\circ}$ (e.g., inset Fig. 3B). Near the northern and southern model boundaries, new shear zones form within the central horst of the first-generation graben, accommodating all the extension in this area. At 13 Ma progressive extension leads to a second generation of narrow grabens rupturing the central region of the model and accommodating extension along a narrow corridor (Fig. 3C). The strike of the active shear zones has rotated to around $7^{\circ}$ coinciding with the minimum instantaneous horizontal strain direction (Fig. $3 \mathrm{C}$ inset). Third-generation highly localized shear zones near the northern and southern model edges highlight initiation of lithospheric breakup, precursor to the future oblique ridge. Finally, at $24 \mathrm{Ma}$ (Fig. 3D) the oblique rift is fully connected and extension is accommodated along an extremely localized oblique ridge that separates two conjugate passive margins where earlier structures are preserved. The oblique ridge strike ranges between 8 and $20^{\circ}$, centered around $16^{\circ}$, and is segmented in two regions connected with a highly oblique transform domain. The 3D structure at depth at $15 \mathrm{Ma}$ is characterized by early offset en-échelon crustal shear zones with limited along strike continuity, extension accommodated in a relatively narrow area, and localized lithospheric thinning close to break-up (Fig. 4A, and 3D animation in supplementary Fig. S7). An animation of the surface strain rate evolution for M1 is available in supplementary Fig. S4.

\section{Model 2 (M2): Moderate Obliquity (weak zone obliquity $=45^{\circ}$ )}

At moderate obliquity the evolving rift system is much more segmented with extensional deformation localizing in multiple normal shear zones within the oblique weak zone (Fig. 3E-H). As extension starts, a wide oblique depression limiting a zone of distributed deformation forms at the surface. The strike and width of the depression are consistent with the imposed oblique weak zone geometry. At $5 \mathrm{Ma}$ (Fig. 3E) extension results in a first generation of isolated $110 \mathrm{~km}$-wide, moderately oblique en-échelon crustal scale grabens. The strike of the active extensional shear zones varies between $8^{\circ}$ and $20^{\circ}$, with a peak around $10^{\circ}$, consistent with the distribution of the intermediate principal stress $\sigma_{2}$. At $10 \mathrm{Ma}$ (Fig. 3F) the first generation of grabens has propagated along strike towards the boundaries of the weak zone where deformation is mostly accommodated along the central segment of the normal shear zones. The orientation of the first generation extensional shear zones has rotated to around $3^{\circ}$. Near the northern and southern model edge a second generation of short and narrow grabens has dissected and replaced the first generation normal shear zones. At 14 Ma (Fig. 3G) a second generation of $50 \mathrm{~km}$-wide grabens accommodates the extension and segments the stretched central domain along a narrow corridor. The distribution of the strike of the active shear zones is bi-modal, with a main extensional shear zones population striking at $0^{\circ}$, orthogonal to the plate motion direction corresponding to rotated phase 1 structures, and a second population of new formed phase 2 shear zones striking around $15^{\circ}$ aligned with $\sigma_{2}$ direction. A third generation of shear zones (phase 3 ) ruptures the lithosphere within the phase 2 grabens near the front and back model edge. At $24 \mathrm{Ma}$ (Fig. $3 \mathrm{H}$ ) extension is accommodated along an oblique ridge striking between $25^{\circ}$ and $38^{\circ}$, centered around $33^{\circ}$, segmented in five regions connected by highly oblique accommodation zones. These accommodation zones crosscut the long-lived phase 1 extensional shear zones. Earlier structures are preserved on the resulting conjugate passive margins. At depth the 3D structure exhibits shorter discontinuous offset normal shear zones in the moderately thinned continental crust, extension is accommodated over a significantly wider area, associated with reduced lithospheric thinning as compared to the low obliquity M1 case (Fig. 4B, and 3D animation in supplementary Fig. S8). An animation of the surface strain rate evolution for M2 is available in supplementary Fig. S5.

\section{Model 3 (M3): High Obliquity (weak zone obliquity $=60^{\circ}$ )}

At high obliquity deformation results in a highly segmented rift system (Fig. 3I-L). At 8.5 Ma extension localizes on a first generation of multiple short and disconnected $110 \mathrm{~km}$-wide offset rift segments (Fig. 3I). The strike of the active first generation normal shear zones is about $18^{\circ}$. With increased extension at $11.5 \mathrm{Ma}$ (Fig. 3J) the central parts of the first generation normal shear zones rotate to $\sim 10^{\circ}$ while the lateral ends of the shear zones remain at their original orientation resulting in multiple isolated en-échelon sigmoid shear zones. At 17 Ma (Fig. 3K) a second generation of narrowly spaced normal shear zones forms at the axis of the rift system. Finally at $30 \mathrm{Ma}$ (Fig. 3L) strain localizes in a very narrow zone with areas of highly oblique lithospheric rupture, oriented at about $51^{\circ}$, separated by accommodation zones with highly extended continental crust. An animation of the surface strain rate evolution for M3 is available in supplementary Fig. S6. At depth 


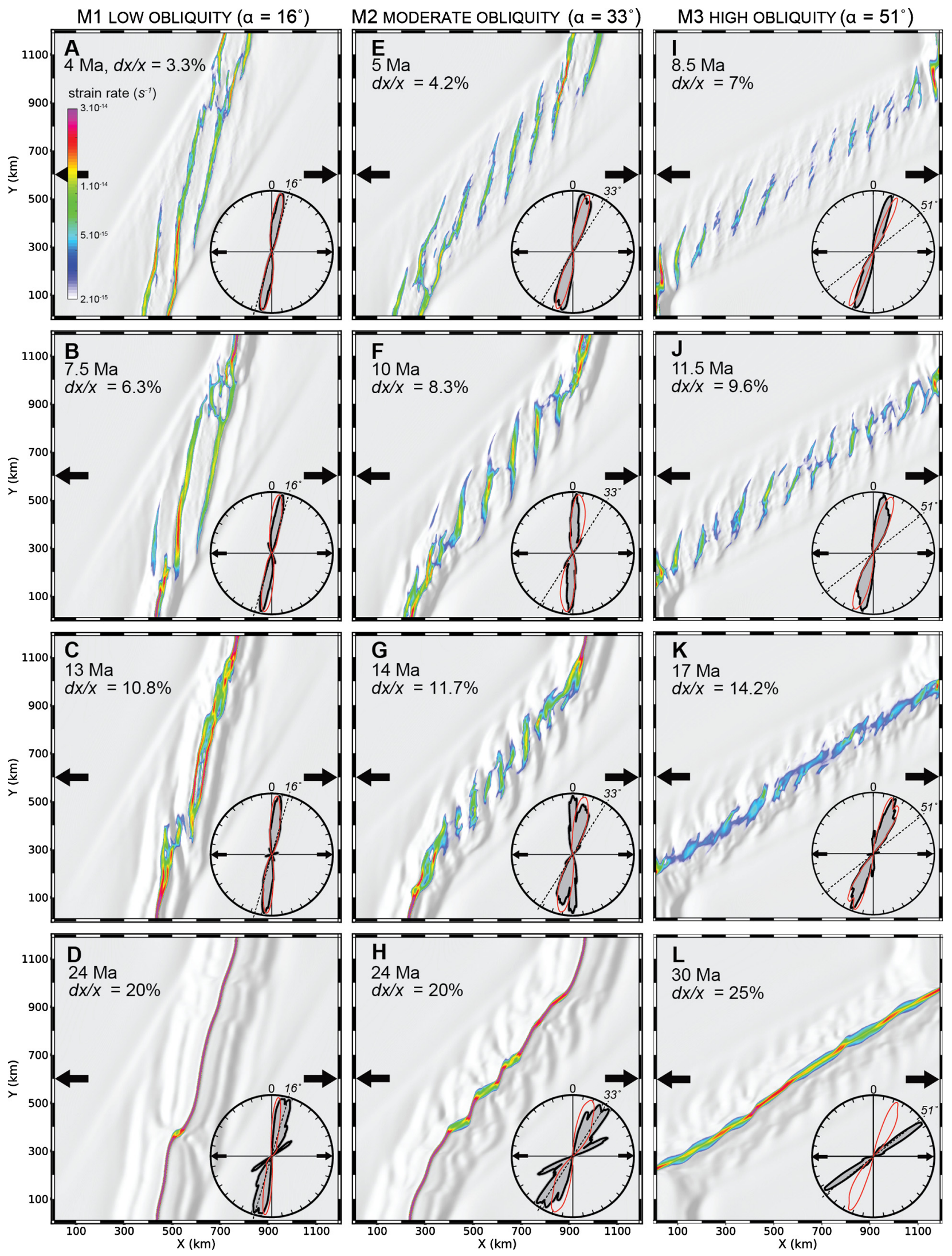

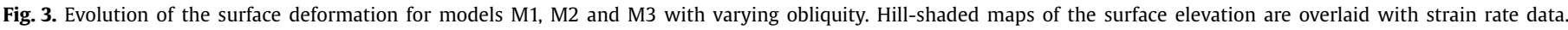

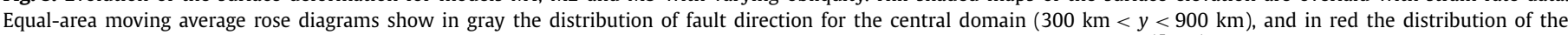

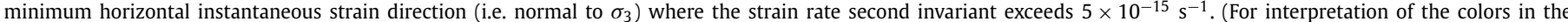
figure(s), the reader is referred to the web version of this article.) 
M1 LOW OBLIQUITY $\left(a=16^{\circ}\right)$

$15 \mathrm{Ma}$
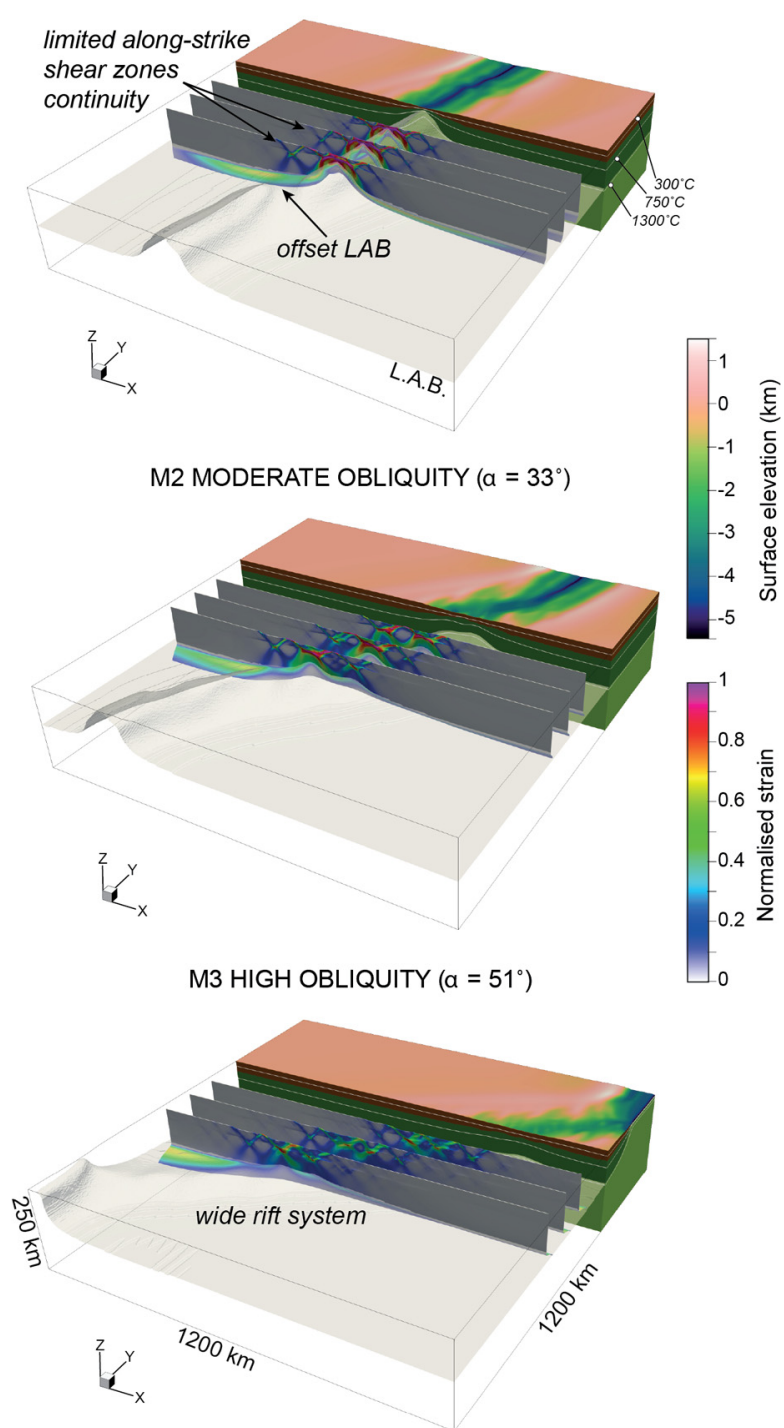

Fig. 4. 3D perspective view at $15 \mathrm{Ma}$ of: (A) the low obliquity model (M1); (B) the intermediate obliquity model (M2); and (C) the high obliquity model (M3). The semi-transparent surface in the mantle represents the interface between the lithospheric and sub-lithospheric mantle (LAB). The three sections highlighting finite strain distribution within each model correspond to deformed Lagrangian sections originally located at 500, 600 and $700 \mathrm{~km}$ along the $y$-axis. 300,750 and $1300^{\circ} \mathrm{C}$ isotherms are displayed on the model surface for reference. See supplementary Figs. S6-S8 for animated perspective views of the models.

the 3D geometry exhibits extension distributed over a $400 \mathrm{~km}$ wide area with multiple horst and graben systems in each rift segment (Fig. 4C, and 3D animation in supplementary Fig. S9). Extension in the crust and mantle lithosphere is accommodated on close to orthogonal normal shear zones. The sub-lithospheric mantle shows, in contrast, important out of plane lateral flow, oblique to the extension direction, accommodating lithosphere thinning in the necking area.

\section{Geometric controls on the rift trend and ridge obliquity}

In all the models presented here, strain localization starts from the edge of the weak zone then propagates inward from the internal corners of the weak zone and the walls. The loci of the strain localization initiation zones along the walls of the model are static and inherently control the rift orientation. Consequently, the general trend of the rift is a function of the weak zone geometry and the model dimensions. We can calculate the rift trend obliquity $\alpha$, as a function of the weak zone across-width $W$ in $\mathrm{km}$, the model length $L$ in $\mathrm{km}$, and the imposed weak zone obliquity $\alpha^{\prime}$ :

$\alpha=\tan ^{-1}\left(\frac{L \tan \alpha^{\prime}-W / \cos \alpha^{\prime}}{L}\right)$

Assuming a $300 \mathrm{~km}$ weak zone (the width of the weak zone central region) and a model length of $1200 \mathrm{~km}$, low obliquity model M1 $\left(\alpha^{\prime}=30^{\circ}\right)$ has a rift trend and final ridge obliquity of $16^{\circ}$ (angle between the ridge and the $y$-axis); intermediate obliquity model M2 $\left(\alpha^{\prime}=45^{\circ}\right)$ has a rift trend and final ridge obliquity of $33^{\circ}$; and high obliquity model M3 $\left(\alpha^{\prime}=60^{\circ}\right)$ has a rift trend and final ridge obliquity of $51^{\circ}$ (see supplementary Fig. S1).

The internal freedom left for structures to develop at a particular orientation within the rift system is bounded to the weak zone geometry. The capacity of the rift system to develop either segmented or connected structures will significantly influence normal shear zones orientations.

\section{Evolution of the orientation of normal shear zones, rift width, and thinning factors}

The orientation at which the normal shear zones form during the first and second order rift segmentation in models 1-3 changes with varying obliquity of the weak zone. For low and intermediate obliquity models M1 and M2, shear zones form at about $10-15^{\circ}$ from the extension orthogonal direction, whereas for M3, at high obliquity they initiate at $20^{\circ}$ (e.g. Fig. 5), close to the predicted intermediate angle between rift trend and the extension direction (e.g., Brune, 2014). For M1, the low obliquity of the rift trend, forced by the geometry of the system, promotes the development of an interconnected rift depression. Because the grabens within this depression are connected, the shear zones orientation remain constant through time (Fig. 5A).

For M2 and M3 (Fig. 5B and $5 \mathrm{C}$ ), following their formation the central part of the normal shear zones delimiting the isolated grabens forming the rift depression, rotate counterclockwise to an azimuth close to extension orthogonal orientation. The final orientation of lithospheric rupture is largely controlled by the location of the internal corners between the weak zone and the model walls.

The active rift width is calculated by measuring the maximum distance between active shear zones across-strike the rift trend $(\alpha)$. The active rift width trends are sensibly similar for the three models (Fig. 5). A first phase of widening of the rift system associated with propagation of the individual normal shear zones towards the boundaries of the weak zone and with finite extension and widening of the first generation rift basins. The widening phase duration appears to decrease with increasing obliquity from $\sim 5$ Ma for M1 to 4 Ma for M2, and 3.5 Ma for M3. A second phase of rift narrowing linked to progressive localization, necking, and weakening of the mantle lithosphere at depth. Conversely to the widening phase, the narrowing phase duration increases with model obliquity. In the three models, narrowing precedes the progressive narrow oblique lithospheric rupture.

After extracting the model surface elevation, the Moho interface depth, and the mantle lithosphere and sub-lithospheric mantle interface depth, we compute the crustal $\beta$ and mantle lithosphere $\delta$ thinning factors based on the equations:

$\beta=1-\frac{H_{c}}{H_{c 0}} \quad \delta=1-\frac{H_{m l}}{H_{m l 0}}$

with $H_{c}$ the continental crust thickness at $t$, and $H_{c 0}$ the initial continental crust thickness $(35 \mathrm{~km}) ; H_{m l}$ the mantle lithosphere thickness at $t$, and $H_{m l 0}$ the initial mantle lithosphere thickness $(90 \mathrm{~km})$. Crust and mantle lithosphere thinning patterns vary with changing obliquity and reflect the structural style of deformation as inferred from structures observed at the surface and at depth 


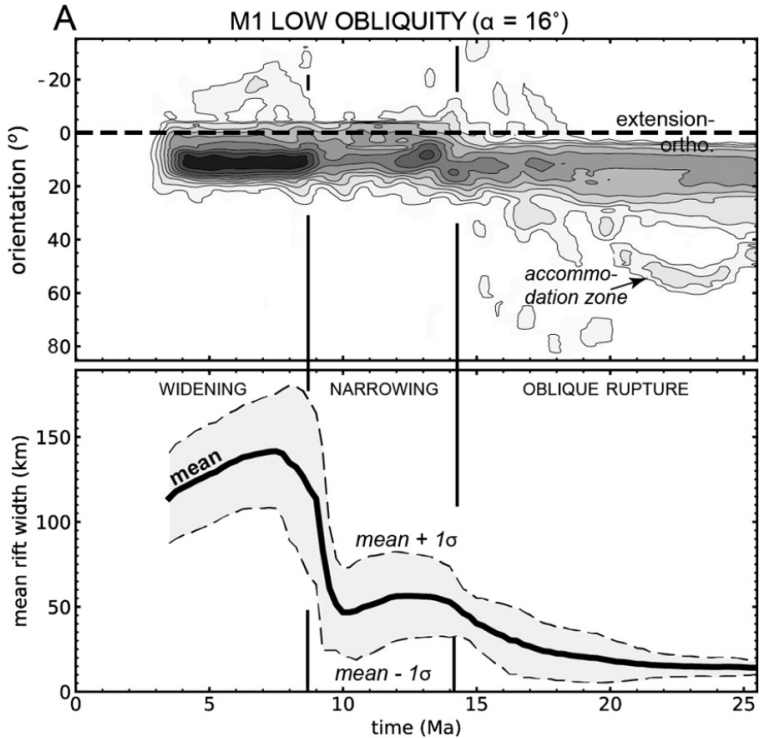

B M2 MODERATE OBLIQUITY $\left(a=33^{\circ}\right)$
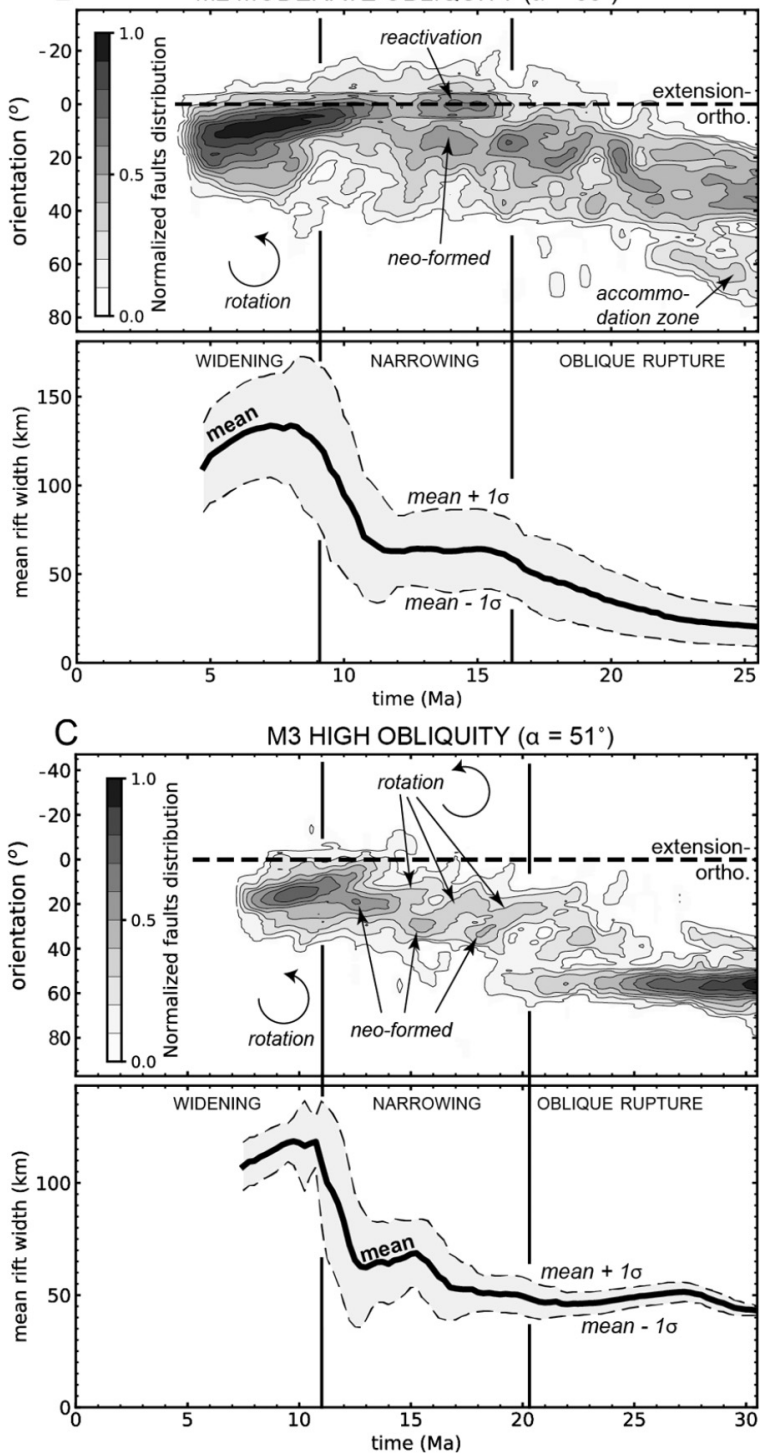

Fig. 5. Top: Frequency analysis of the active faults orientation distribution (normalized to the cumulated fault length) for the moderately oblique model's central domain $(300 \mathrm{~km}<y<900 \mathrm{~km}$ ). Bottom: Mean width of the active rift system. Note the progressive rotation of structures during the widening phase and the two-fold distribution of the shear zones orientation upon narrowing.
(Fig. 6). Both crustal and mantle lithosphere thinning patterns for the three models are asymmetric and limited to the weak zone region. The distribution of mantle lithosphere thinning prior to break-up with large wavelength thinning patterns appears to be largely controlled by strain accumulated during first order rift segmentation, whereas the pattern of crustal thinning shows the superposition of both widely spaced phase 1 and narrow phase 2 segmentation. Thinning factors distribution indicate that passive margins formed during oblique rifting are characterized with $\mathrm{V}$ shaped structures corresponding to abandoned isolated grabens, later connected during break-up.

\section{Discussion}

We first summarize the evolution of the surface deformation for the moderately oblique rift model and develop a generic scheme for the evolution of oblique-rifted extensional systems. While largely based on M2 the generic scheme can easily be generalized to systems with varying obliquity. Then, we discuss the underlying processes controlling the geometry of the structures, and finally compare our results with natural examples of moderately oblique rifts.

\section{Surface deformation sequence}

We use intermediate obliquity model M2 to identify four characteristic phases of deformation (Fig. 7). (1) The initiation Phase (Fig. 7A) shows distributed deformation limited to the oblique weak zone. With increasing strain, frictional-plastic weakening promotes the development of a first generation of conjugate normal shear zones at the model sides that propagate obliquely within the model. (2) First order segmentation phase 1 (Fig. 7B) with strain partitioning between the frictional plastic shear zones segmenting the continental lithosphere progressively into isolated upper crustal blocks. Isolated oblique extensional shear zones limit wide en-échelon grabens, oriented orthogonal to the minimum principal stress $\sigma_{3}$ and the maximum instantaneous stretching direction. Within the isolated grabens slip on the extensional shear zones is limited to the central segments, which progressively rotate to become orthogonal to the plate motion direction. (3) Phase 2 second order segmentation (Fig. 7C) is characterized by the development of new grabens with smaller wavelength that interconnect the rift. These grabens combine two shear zones populations with inherited extension-orthogonal shear zones alternating with new-formed moderately oblique shear zones combined into a suite of orthorhombic systems. (4) Finally, oblique rupture phase 3 (Fig. 7D) leads to 'oceanic' domains that propagate from the model edges and merge with isolated incipient 'oceanic' sub-basins forming a continuous sigmoid ridge system where highly oblique and highly stretched crustal accommodation zones link intermediate oblique ridge segments. This characteristic sequence applies as well to systems with low or high obliquity. The main effect of varying obliquity of a pre-existing weak zone is on the along-strike length of the individual faults segments, with low obliquity promoting fewer and longer along-strike sets of normal faults, and high obliquity resulting in many short en-échelon faults.

\section{Deformation style: controls and underlying processes}

We recognize three main factors that control the structural style of deformation in the model: (1) the geometry of the weak zone, (2) the strain weakening parameterization, and (3) the rheological layering of the model. The relative influence of these factors controls the structural style of oblique rifting. The duration of the initiation phase depends primarily on the efficiency of frictional plastic strain localization, in our model controlled by the strain weakening function (e.g., Huismans and Beaumont, 2003). Along the north and south walls the free-slip condition imposes planestrain deformation, inducing a rapid increase in the accumulation 




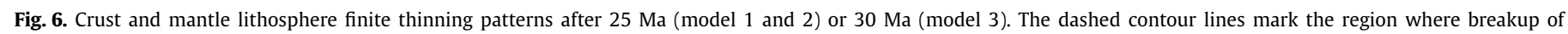
the continental crust is complete and mantle material reached the surface.

of plastic strain in the brittle layers and leading to early localization. With these boundary conditions the position of the first generation of extensional shear zones that form at the internal corners between the weak zone and the model walls is consistent with Allken et al. (2012) findings that show that self-organization of non-linked faults tend to promote the shortest path between the necking regions along the opposite walls of the model. In addition, the oblique geometry of the weak zone facilitates the inward propagation of the deformation from the model walls.

Within the weak zone, the stress field rotates due to the strength contrast with its surroundings. When they form, phase 1 and phase 2 dip-slip extensional shear zones (Fig. 3A, 3C, 5, S3) are oriented at $\sim 75^{\circ}$ from the extension vector, corresponding to an intermediate angle between the rift trend and the plate motion direction (Withjack and Jamison, 1986; Brune and Autin, 2013; Brune, 2014). Our models, however, show that progressive deformation during Phase 1 extension results in rotation of the extensional shear zones to become orthogonal to the plate motion direction and control the structural style during oblique rifting. Although the stress around the active extensional shear zones rotate (Fig. 3), the progressive rotation of Phase 1 extensional shear zones during widening (Fig. 5) forces a discrepancy between $\sigma_{2}$ direction and the strike of the structures that must be accommodated by a minor component of strike slip. Early rift structures are thus critical in controlling the final architecture of oblique-rifted margins, but because of potential rotations they must be used with caution when interpreting the tectonic evolution of passive margins. This result indicates that while oblique rift trend remains stable through time, as it is imposed by the model geometry and boundary conditions, internal structures rotate in order to efficiently accommodate thinning of the crust and lithosphere.
In the three models presented here, oblique rifts develop with alternating asymmetry visible as shown in the thinning maps (Fig. 6). This characteristic thinning pattern confirms earlier 3D model predictions (e.g., van Wijk, 2005) that oblique rifts are expected to develop with alternating asymmetry, and show that such asymmetric thinning patterns should be preserved after break-up on the passive margins of the rifts.

Spacing of the extensional shear zones is controlled by the effective thickness of the competent layer(s) in the model at the time of localization (Soliva and Benedicto, 2005). During phase 1 segmentation, the effective competent layering includes the crust plus the top 20 kilometers of the mantle lithosphere (Fig. 1). In our model extensional shear zones dip on average at $45^{\circ}$ (e.g., Kaus, 2010), thus the thickness of the effective frictional plastic layer directly controls the $110 \mathrm{~km}$ width of the grabens. During phase 2 segmentation progressive rise of the hot and weak sub-lithospheric mantle modifies the rheological layering in the system beneath the rift axis and exerts a strong control on the width of the active deformation region resulting in narrowing of the active deformation. The increasing geothermal gradient beneath the rift axis reduces the effective frictional-plastic layer to the upper crust forcing the wavelength of second-order phase 2 grabens to narrow to $50 \mathrm{~km}$. Accordingly, the number, size, and extent of isolated grabens is controlled by the rheological layering of the lithosphere, the width and the obliquity of the weak zone as observed in analog experiments (Agostini et al., 2009).

Upon lithospheric rupture, the weak sub-lithospheric mantle accommodates most of the extension in the system and the active deformation region is very narrow. Accommodation zones crosscut the long-lived phase 1 extensional shear zones while oblique 'oceanic' ridges bisect the phase 2 oblique grabens. 


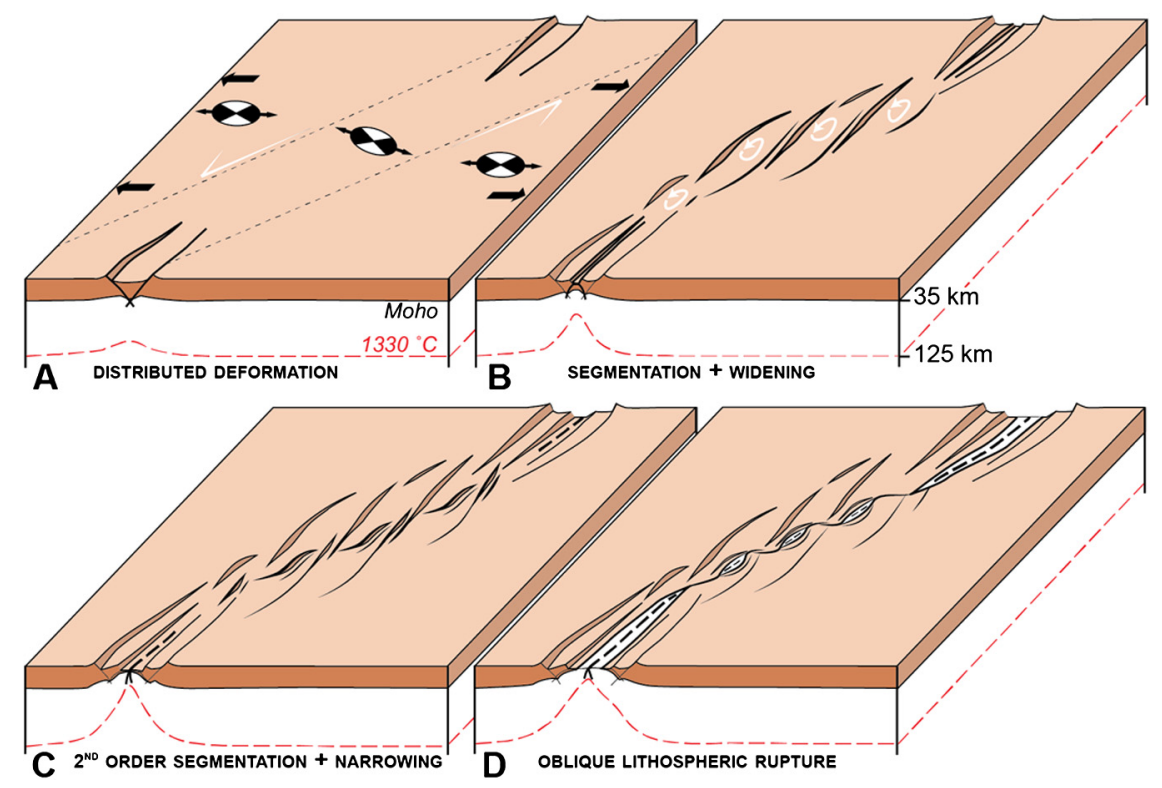

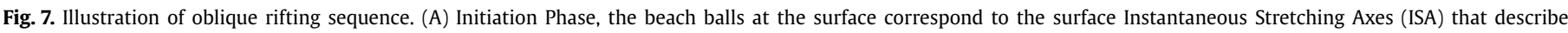

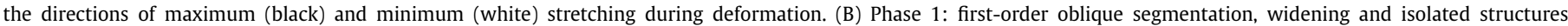
rotation; (C) Phase 2: rift narrowing and second-order segmentation; (D) Phase 3: oblique rupture and development of step-like passive margins.

\section{Comparison to natural systems}

Our results suggest that interaction between phase 1 and phase 2 extensional shear zones results in complex strain partitioning during oblique rifting. Along the oblique rift axis, enéchelon phase 1 extensional shear zones form at an intermediate orientation between the rift trend and the normal to the plate motion direction and locally rotate to become close to normal to the plate motion direction, thus accommodating maximum stretching of the lithosphere before narrowing starts during Phase 2. Similar deformation patterns have been described in active oblique continental rifts and passive margin systems (e.g. Fig. 1). The MER depression (Fig. 1A) trends at a moderate obliquity from the extending Nubia and Somalia plate motion direction. The rift depression width is comparable to the phase 1 grabens formed in our models. The depression itself, delimited by the Miocene Boundary faults, oriented at about 10 to $25^{\circ}$ from the orthogonal to the plate motion direction, is curved in its center and shows asymmetric margins. The variability in the Boundary faults orientation could well reflect local rotation of the central part of the Boundary faults, associated with the progressive thinning of the active rift. This is compatible with the slip re-orientation hypothesis proposed by Philippon and Corti (2016) and later discussed by Sani et al. (2019). We argue that the MER has reached stage 2 of the model we propose here. The phase 2 second-order segmentation and the development of extension-orthogonal structures observed in our models form an analog to the Quaternary extension-orthogonal Wonji faults that correspond to the active structures distributed en-échelon within the MER depression (Fig. 1A; Agostini et al., 2011; Corti et al., 2013; Philippon et al., 2015). This inward migration of active deformation occurred after $\sim 20 \mathrm{~km}$ of overall extension (Agostini et al., 2009), a magnitude similar to the widening phase of models M2 and M3 (Fig. 5B and 5C). Although high, the resolution of the numerical models is not sufficient to replicate the development of small extension orthogonal shear zones like the Wonji faults. Interestingly, both Boundary and Wonji faults, while slightly oblique from each other, exhibit almost pure dip slip kinematics (e.g. Keir et al., 2006; Philippon et al., 2015). A surface analysis of the orientation of the principal stress tensor for model M2 during phase 2 confirms that deformation along the active structures are normal shear zones dominated by dip-slip kinemat- ics, irrespectively of their orientations (Blue regions in Fig. S3). In addition, it is important to note that volcanism in this region, close to the Afar hotspot, must contribute to additional thermal weakening of the lithosphere (Ebinger and Sleep, 1998) facilitating the development of extension orthogonal structures.

The Gulf of Aden displays an intermediate oblique trend with respect to the plate motion direction associated with the rifting between Arabia and Somalia. The Gulf orientation is controlled by the Afar hotspot in the SW and the Owen oceanic transform system in the NE on its boundaries. However, extension-orthogonal and intermediate oblique faults populations identified on the eastern part of the Gulf of Aden conjugate margins (e.g. Fig. 1B; Autin et al., 2010) are consistent with phase 1 and phase 2 structures. Structures oriented obliquely and sub-orthogonally to plate motion direction formed during Oligo-Miocene rifting control the segmented geometry of the coastline and ocean-continent transition zone along the conjugate passive margins (Agostini et al., 2009; Autin et al., 2013; Bellahsen et al., 2013) as observed in our model. Extension orthogonal structures are dominant in this region of the Gulf, even toward the edge of the depression. This is different from our models and could be related to fact that Oligo-Miocene rifting reactivates en-échelon Mesozoic basins oriented orthogonally to the Cenozoic rifting plate motion direction. Still, the dimension of the Oligo-Miocene en-échelon sedimentary basins is very similar to the phase 1 en-échelon grabens observed in models M2 and M3. The asymmetric V-shaped of the thinning factors observed along model M2 passive margins (Fig. 6) is strikingly similar to the asymmetric V-shape of the segmented geometry of the coastline and ocean-continent transition zone on the conjugate margins of the East-Aden and Shebba ridges (Autin et al., 2010).

\section{Limitations}

The numerical models presented here are purposely simple and already require very large computational resources to compute. The range of physical processes solved within the code neither include surface processes, nor magmatism which both could have a strong effect on strain localization over the lifespan of a rift system (e.g. Burov and Cloetingh, 1997; Olive et al., 2014). The geometry of the inherited structure is also very simple and solely aims to localize rift deformation in an oblique zone. We did not explore the effect of localized inherited shear zones or the impact 
of lateral rheological heterogeneities in the model (like cratonic domains, or mantle plumes) (e.g. Koptev et al., 2015, 2016). The imposed boundary conditions have an important impact on the localization pattern developing at the model edges. Upon breakup, when the ridge propagates from the sides of the model, we note that the three models do not reproduce real transform structures, oriented parallel to the extension direction and linking the active ridge segments (Gerya, 2010, 2013). Finally, we only tested one set of thermal and rheological conditions, and more work would be required to test the sensitivity of changes in crust and mantle rheologies for controlling the evolution of normal fault structures formed during oblique extension.

\section{Conclusion}

We use high-resolution 3D thermo-mechanical modeling to investigate the structural style of deformation during oblique rift and passive margin formation. We draw the following conclusions.

1. In our models the oblique trend of rift systems is controlled by the geometry of pre-existing weak structures and imposed boundary conditions.

2. The forward models presented here indicate that structures formed within these obliquely extending domains, follow a moderately oblique trend.

3. Model results presented here suggest that oblique rift systems exhibit three characteristic phases of deformation. (1) First order rift segmentation (phase 1) with formation of moderatelyoblique segmented en-échelon normal faults within the imposed weak zone with a spacing in the order of $110 \mathrm{~km}$ reflecting the model initial lithospheric rheological layering. (2) Second order rift segmentation (phase 2) with shorter normal faults segments with a characteristic spacing of $\sim 50 \mathrm{~km}$ reflecting an upper crustal layer thickness control and reduced influence of the thinned and weakened mantle lithosphere. (3) Lithospheric rupture resulting in linked oblique ridge segments.

4. The model results predict that normal faults, during oblique rifting, form at $10-20^{\circ}$ to the extension orthogonal direction.

5. Progressive extension and finite deformation rotate early moderately-oblique structures to close to the extension orthogonal direction.

6. The models suggest that rift width varies with changing obliquity of the inherited weak zone promoting more distributed deformation for high obliquity systems.

7. The distribution of mantle lithosphere thinning prior to breakup is largely controlled by strain accumulated during first order rift segmentation, whereas the distribution of crustal thinning results from the superposition of both widely spaced phase 1 and narrow phase 2 segmentation.

8. The inferred behavior is consistent with observations from two natural systems. Within the curved trend of the MER depression, new normal faults follow a close to extension orthogonal trend, consistent with model predictions for early stage 2 . The Gulf of Aden displays an oblique trend controlled by far field boundary controls of the Afar hotspot in the SW and the Owen oceanic transform system in the NE. However, margin structure including rift normal faults and the ocean continent boundary are close to orthogonal to the present-day direction of plate divergence, consistent with our model results.

\section{Declaration of competing interest}

The authors declare that they have no known competing financial interests or personal relationships that could have appeared to influence the work reported in this paper.

\section{Acknowledgements}

This study is part of the Barents Sea Paleozoic basement and basin configurations (BarPz) project funded by the Research Council of Norway's PetroMaks2 program. Computing hours are part of Notur HPC allocation project NN4704K: 3D forward modeling of lithosphere extension. We are grateful to NTNU HPC support team for their assistance with Vilje supercomputer. DAM acknowledges financial support from the European Research Council under the European Union's Seventh Framework Programme (FP7/2007-2013)/ERC Grant Agreement Number 279925 and the Alfred P. Sloan Foundation through the Deep Carbon Observatory Modeling and Visualization Forum. Sascha Brune and two anonymous reviewers are greatly acknowledged for their constructive revisions.

\section{Appendix A. Supplementary material}

Supplementary material related to this article can be found online at https://doi.org/10.1016/j.epsl.2019.115952.

\section{References}

Agostini, A., Corti, G., Zeoli, A., Mulugeta, G., 2009. Evolution, pattern, and partitioning of deformation during oblique continental rifting: inferences from lithospheric-scale centrifuge models. Geochem. Geophys. Geosyst. 10 (11). 23 p.

Agostini, A., Bonini, M., Corti, G., Sani, F., Manetti, P., 2011. Distribution of Quaternary deformation in the central main Ethiopian rift, East Africa. Tectonics 30, TC4010.

Allken, V., Huismans, R.S., Thieulot, C., 2012. Factors controlling the mode of rift interaction in brittle-ductile coupled systems: a 3D numerical study. Geochem. Geophys. Geosyst. 13 (5)

Autin, J., Bellahsen, N., Husson, L., Beslier, M.O., Leroy, S., d'Acremont, E., 2010. Ana$\log$ models of oblique rifting in a cold lithosphere. Tectonics 29 (6), TC6016.

Autin, J., Bellahsen, N., Leroy, S., Husson, L., Beslier, M.O., d'Acremont, E., 2013. The role of structural inheritance in oblique rifting: insights from analogue models and application to the Gulf of Aden. Tectonophysics 607, 51-64.

Bellahsen, N., Husson, L., Autin, J., Leroy, S., d'Acremont, E., 2013. The effect of thermal weakening and buoyancy forces on rift localization: field evidences from the Gulf of Aden oblique rifting. Tectonophysics 607, 80-97.

Bergerat, F., Angelier, J., Villemin, T., 1990. Fault systems and stress patterns on emerged oceanic ridges: a case study in Iceland. Tectonophysics 179, 183-197.

Brune, S., Popov, A.A., Sobolev, S.V., 2012. Modeling suggests that oblique extension facilitates rifting and continental break-up. J. Geophys. Res., Solid Earth 117 (B8), 1978-2012.

Brune, S., Autin, J., 2013. The rift to break-up evolution of the Gulf of Aden: insights from 3D numerical lithospheric-scale modelling. Tectonophysics 607, 65-79.

Brune, S., 2014. Evolution of stress and fault patterns in oblique rift systems: 3-D numerical lithospheric-scale experiments from rift to breakup. Geochem. Geophys. Geosyst. 15 (8), 3392-3415.

Brune, S., Williams, S.E., Müller, R.D., 2018. Oblique rifting: the rule, not the exception. Solid Earth 9 (5), 1187-1206.

Burov, E., Cloetingh, S.A.P.L., 1997. Erosion and rift dynamics: new thermomechanical aspects of post-rift evolution of extensional basins. Earth Planet. Sci. Lett. 150 (1-2), 7-26.

Chorowicz, J., Sorlien, C., 1992. Oblique extensional tectonics in the Malawi Rift, Africa. Geol. Soc. Am. Bull. 104 (8), 1015-1023.

Clifton, A.E., Schlische, R.W., Withjack, M.O., Ackermann, R.V., 2000. Influence of rift obliquity on fault-population systematics: results of experimental clay models. J. Struct. Geol. 22 (10), 1491-1509.

Corti, G., Philippon, M., Sani, F., Keir, D., Kidane, T., 2013. Re-orientation of the extension direction and pure extensional faulting at oblique rift margins: comparison between the Main Ethiopian Rift and laboratory experiments. Terra Nova 25 (5), 396-404.

Dewey, J.F., Holdsworth, R.E., Strachan, R.A., 1998. Transpression and transtension zones. Geol. Soc. (Lond.) Spec. Publ. 135 (1), 1-14.

Ebinger, C.J., Sleep, N.H., 1998. Cenozoic magmatism throughout east Africa resulting from impact of a single plume. Nature 395 (6704), 788.

Fossen, H., Khani, H.F., Faleide, J.I., Ksienzyk, A.K., Dunlap, W.J., 2016. PostCaledonian extension in the West Norway-northern North Sea region: the role of structural inheritance. Geol. Soc. (Lond.) Spec. Publ. 439, SP439-6.

Gapais, D., Cobbold, P.R., Bourgeois, O., Rouby, D., de Urreiztieta, M., 2000. Tectonic significance of fault-slip data. J. Struct. Geol. 22, 881-888.

Gerya, T., 2010. Dynamical instability produces transform faults at mid-ocean ridges. Science 329 (5995), 1047-1050. 
Gerya, T., 2013. Three-dimensional thermomechanical modeling of oceanic spreading initiation and evolution. Phys. Earth Planet. Inter. 214, 35-52.

Gleason, G.C., Tullis, J., 1995. A flow law for dislocation creep of quartz aggregates determined with the molten salt cell. Tectonophysics 247, 1-23.

Huismans, R.S., Beaumont, C., 2002. Asymmetric lithospheric extension: the role of frictional plastic strain softening inferred from numerical experiments. Geology 30 (3), 211-214.

Huismans, R.S., Beaumont, C., 2003. Symmetric and asymmetric lithospheric extension: relative effects of frictional-plastic and viscous strain softening. J. Geophys. Res. 108, 2496.

Huismans, R.S., Beaumont, C., 2007. Roles of lithospheric strain softening and heterogeneity in determining the geometry of rifts and continental margins. In: Karner, G.D., Manatschal, G., Pinhiero, L.M. (Eds.), Imaging, Mapping and Modelling Continental Lithosphere Extension and Breakup. Geol. Soc. (Lond.) Spec. Publ. 282, 107-134.

Huismans, R.S., Beaumont, C., 2011. Depth-dependent extension, two-stage breakup and cratonic underplating at rifted margins. Nature 473 (7345), 74-78.

Karato, S.I., Wu, P., 1993. Rheology of the upper mantle: a synthesis. Science 260, $771-778$.

Kaus, B.J., 2010. Factors that control the angle of shear bands in geodynamic numerical models of brittle deformation. Tectonophysics 484 (1), 36-47.

Keir, D., Ebinger, C.J., Stuart, G.W., Daly, E., Ayele, A., 2006. Strain accommodation by magmatism and faulting as rifting proceeds to breakup: seismicity of the northern Ethiopian rift. J. Geophys. Res. 111, B05314.

Knudsen, B.E., Liljedahl, T., Midbøe, P.S., Søderstrøm, B., 1997. Oblique rifting and sequential faulting in the Jurassic development of the northern North Sea. J. Struct. Geol. 19 (10), 1285-1302.

Koptev, A., Calais, E., Burov, E., Leroy, S., Gerya, T., 2015. Dual continental rift systems generated by plume-lithosphere interaction. Nat. Geosci. 8 (5), 388-392.

Koptev, A., Burov, E., Calais, E., Leroy, S., Gerya, T., Guillou-Frottier, L., Cloetingh, S. 2016. Contrasted continental rifting via plume-craton interaction: applications to Central East African Rift. Geosci. Front. 7 (2), 221-236

Le Pourhiet, L., May, D.A., Huille, L., Watremez, L., Leroy, S., 2017. A genetic link between transform and hyper-extended margins. Earth Planet. Sci. Lett. 465, 184-192.

Leroy, S., Razin, P., Autin, J., Bache, F., d'Acremont, E., et al., 2013. From rifting to oceanic spreading in the Gulf of Aden: a synthesis. In: Lithosphere Dynamics and Sedimentary Basins: The Arabian Plate and Analogues. Springer Berlin Heidelberg, pp. 385-427.

Liao, J., Gerya, T., 2015. From continental rifting to seafloor spreading: insight from 3D thermo-mechanical modeling. Gondwana Res. 28 (4), 1329-1343.

Lizarralde, D., Axen, G.J., Brown, H.E., Fletcher, J.M., González-Fernández, A., Harding, A.J., Holbrook, W.S., Kent, G.M., Paramo, P., Sutherland, F., Umhoefer, P.J., 2007. Variation in styles of rifting in the Gulf of California. Nature 448 (7152), 466.
May, D.A., Brown, J., Le Pourhiet, L., 2014. pTatin3D: high-performance methods for long-term lithospheric dynamics. In: Proceedings of the International Conference for High Performance Computing, Networking, Storage and Analysis. IEEE Press, pp. 274-284.

May, D.A., Brown, J., Le Pourhiet, L., 2015. A scalable, matrix-free multigrid preconditioner for finite element discretizations of heterogeneous Stokes flow. Comput. Methods Appl. Mech. Eng. 290, 496-523.

McClay, K.R., Dooley, T., Whitehouse, P., Mills, M., 2002. 4-D evolution of rift systems: insights from scaled physical models. Am. Assoc. Pet. Geol. Bull. 86 (6), 935-960.

Mondy, L., Rey, P., Duclaux, G., Moresi, L., 2017. The role of asthenospheric flow during rift propagation and breakup. Geology 46 (2), 103-106.

Olive, J.A., Behn, M.D., Malatesta, L.C., 2014. Modes of extensional faulting controlled by surface processes. Geophys. Res. Lett. 41 (19), 6725-6733.

Philippon, M., Willingshofer, E., Sokoutis, D., Corti, G., Sani, F., Bonini, M., Cloetingh, S., 2015. Slip re-orientation in oblique rifts. Geology 43 (2), 147-150.

Philippon, M., Corti, G., 2016. Obliquity along plate boundaries. Tectonophysics 693, $171-182$.

Pysklywec, R.N., Beaumont, C., 2004. Intraplate tectonics: feedback between radioactive thermal weakening and crustal deformation driven by mantle lithosphere instabilities. Earth Planet. Sci. Lett. 221 (1), 275-292.

Sani, F., Bonini, M., Corti, G., Moratti, G., 2019. Extension direction re-orientation in the oceanic rift of Iceland, and comparison with continental rifts. Tectonophysics 756, 25-42.

Soliva, R., Benedicto, A., 2005. Geometry, scaling relations and spacing of vertically restricted normal faults. J. Struct. Geol. 27 (2), 317-325.

Tron, V., Brun, J.P., 1991. Experiments on oblique rifting in brittle-ductile systems. Tectonophysics 188 (1), 71-84.

Umhoefer, P., Stone, K., 1996. Description and kinematics of the SE Loreto basin fault array, Baja California Sur, Mexico: a positive field test of oblique-rift models. J. Struct. Geol. 18 (5), 595-614.

van Wijk, J.W., 2005. Role of weak zone orientation in continental lithosphere extension. Geophys. Res. Lett. 32 (2).

Warren, C.J., Beaumont, C., Jamieson, R.A., 2008. Modelling tectonic styles and ultrahigh pressure (UHP) rock exhumation during the transition from oceanic subduction to continental collision. Earth Planet. Sci. Lett. 267 (1-2), 129-145.

Withjack, M.O., Jamison, W.R., 1986. Deformation produced by oblique rifting. Tectonophysics 126 (2), 99-124.

Zwaan, F., Schreurs, G., Naliboff, J., Buiter, S.J., 2016. Insights into the effects of oblique extension on continental rift interaction from 3D analogue and numerical models. Tectonophysics. 